\title{
Excessive maternal weight and practice of exclusive breastfeeding among women of low socioeconomic status
}

\author{
Excesso de peso gestacional e prática de \\ aleitamento materno exclusivo entre \\ mulheres de baixo nível socioeconômico
}

Camila DALLAZEN ${ }^{1}$

Márcia Regina VÍTOLO'

\section{A B S T R A C T}

\section{Objective}

To investigate the impact of excessive maternal weight on the early discontinuation of exclusive breastfeeding.

\section{Methods}

This is a longitudinal study including mother-infant dyads of low socioeconomic status receiving prenatal care in Health Care Centers in Porto Alegre, Rio Grande do Sul, Brazil. A structured questionnaire was administered to women in the last trimester of pregnancy, including weight measurements. Another interview was conducted six months after delivery, and data on infant feeding practices were collected and maternal height was measured. Maternal nutritional status was assessed using body mass index values according to gestational age. Discontinuation of exclusive breastfeeding before 4 months was considered a low duration rate.

\section{Results}

A total of 619 mother-infant dyads were evaluated. The prevalence of maternal overweight in the third trimester of pregnancy was $51 \%$. The median duration of exclusive breastfeeding was 2.0 months. After adjustment for possible confounding factors, no association between maternal overweight and early discontinuation of exclusive breastfeeding was identified. Maternal smoking was identified as a risk factor $(1.23,95 \% \mathrm{Cl}=1.13-1.35)$ for early discontinuation of exclusive breastfeeding.

\section{Conclusion}

Excessive maternal weight was not confirmed as a risk factor for early discontinuation of exclusive breastfeeding. However, women who reported being smokers had a higher risk of early discontinuation of exclusive breastfeeding

\footnotetext{
${ }^{1}$ Universidade Federal de Ciências da Saúde de Porto Alegre, Programa de Pós-Graduação em Nutrição, Núcleo de Pesquisa em Nutrição. R. Sarmento Leite, 245, Prédio III, $8^{\circ}$ andar, Sala 802, Centro, 90050-170, Porto Alegre, RS, Brasil. Correspondência para/Correspondence to: C DALLAZEN. E-mail: <camiladallazen@gmail.com>.
} 
than those who did not smoke. This indicates the need for public health interventions to promote smoking cessation during pregnancy and in the postpartum period because of the deleterious effects of this habit on maternal and infant health.

Keywords: Breast feeding. Obesity. Pregnancy.

\section{R E S U M O}

\section{Objetivo}

Investigar o impacto do excesso de peso gestacional na interrupção precoce do aleitamento materno exclusivo.

\section{Métodos}

Estudo longitudinal com binômios mãe-filho de baixo nível socioeconômico atendidos em Unidades de Saúde de Porto Alegre, Brasil. Foi aplicado questionário estruturado às mulheres no último trimestre de gestação com mensuração de peso. Seis meses após o parto ocorreu nova entrevista onde foram obtidos dados sobre prática alimentar da criança e a altura materna foi mensurada. O estado nutricional gestacional foi avaliado por meio do indice de massa corporal de acordo com a idade gestacional. Foi considerada interrupção precoce do aleitamento materno exclusivo a interrupção anterior aos 4 meses de vida da criança.

\section{Resultados}

Analisaram-se 619 binômios mãe-filho. A prevalência de excesso de peso no terceiro trimestre de gestação foi de 51\%. A duração mediana do aleitamento materno exclusivo foi de 2,0 meses. Após análise ajustada, não foi identificado efeito do excesso de peso gestacional na interrupção precoce do aleitamento materno exclusivo. Em contrapartida, o tabagismo materno foi identificado como fator de risco $(1,23,1 C 95 \%=1,13-1,35)$ para interrupção precoce do aleitamento materno exclusivo.

\section{Conclusão}

O excesso de peso materno não confirmou-se como fator de risco para interrupção precoce do aleitamento materno exclusivo. Contudo, as mulheres que se declararam fumantes apresentaram maior risco de interromper a prática do que aquelas que não fumavam. Isso reforça a necessidade de ações de saúde pública as quais promovam a cessação do tabagismo no período gestacional e no puerpério em virtude das consequências deletérias deste hábito à saúde materno-infantil.

Palavras-chave: Aleitamento materno. Obesidade. Gravidez.

\section{NTRODUCTION}

\section{Exclusive Breastfeeding (EBF) for six} months and continued breast feeding complemented with other foods for up to two years is one of the most effective ways to ensure healthy growth and development of a child'. In Brazil, although national data have shown a gradual increase in prevalence of $\mathrm{EBF}^{2}$, most women initiate breastfeeding but they tend to maintain it only for a short period of time ${ }^{3}$; this practice has been more evident especially among overweight nursing mothers ${ }^{4,5}$. There is evidence that obese women, regardless of the gestational weight gain, are less likely to initiate breastfeeding 4 or they breastfeed for a shorter period of time when compared to eutrophic women ${ }^{5}$.

The effect of excessive maternal weight on the duration of breastfeeding is multifactorial and may be associated with: physiological aspects - such as decreased production of prolactin, the hormone responsible for milk ejection ${ }^{6}$ - anatomical aspects - such as very large breasts, often with the presence of flat nipples, which can make latching-on more difficult ${ }^{7}$ - and psychological effects - such as low self-esteem ${ }^{8}$ and postpartum depression ${ }^{9}$. However, despite the wide range of studies addressing the possible effect of maternal overweight on breastfeeding, the evidence is still controversial ${ }^{10}$. Studies have shown that the effect of obesity on breastfeeding 
has little importance when other factors such as parity, marital status, education level, and smoking during pregnancy are taken into account $^{4}$, indicating that the initiation of and duration of breastfeeding are influenced by multiple factors besides the maternal overweight.

In Brazil, studies on the relationship between maternal obesity and breastfeeding practices are scant. In one of the few identified studies addressing this topic, the authors found a positive association between pre-pregnancy obesity and early discontinuation of exclusive breastfeeding within the first month after delivery. However, this association was observed only among obese women $\left(\mathrm{BMl} \geq 30 \mathrm{~kg} / \mathrm{m}^{2}\right)^{11}$. Thus, in view of the current scenario in Brazil, where one out of every two women are overweight ${ }^{12}$, and seeking more conclusive evidence on this topic, the present study aimed to investigate the impact of excessive maternal weight on the early discontinuation of EBF among low socioeconomic status women receiving prenatal care in Health Care Centers in Porto Alegre (RS), Brazil.

\section{METHODS}

This is a prospective longitudinal cohort study nested within a cluster randomized controlled field trial that aimed to assess the impact of the program "Dez passos para uma alimentação saudável: guia alimentar para crianças menores de dois anos"13 by providing training to professionals in Health Care Centers ( $\mathrm{HCC})$ on nutrition and health of children during the first year of life.

The eligible HCC to participate in the baseline study were those that provided health care services to more than 100 children less than one year old in 2006. On the other hand, the HCC participating in the Programa Saúde da Familia (Family Health Program) or that had a provider agreement with other health care and education institutions or with businesses were considered ineligible to participate. Two HCC were randomly selected in each one of the eight regions of the city for the intervention group or control group, totaling 16 Health Care Centers. The selection of the HCC between these groups was made randomly by drawing sealed envelopes. Four other eligible HCC were included during the study to obtain the required sample size, resulting in a total of 20 participant Health Care Centers.

Sample size calculation was made based on the objective of the cluster randomized controlled field trial (increase the duration of exclusive breast feeding in the intervention group compared to that of the control group). Power of $90 \%$, confidence level of $95 \%$, and cluster correlation coefficient of 1.5 were considered to calculate the appropriate sample size, resulting in 300 mother-infant dyads in each group (intervention and control). Considering the predicted dropout rate of $20 \%$, the total of 720 mother-infant dyads was determined as the appropriate sample size.

The intervention in the baseline study consisted on providing training to all health care professionals working in the health care centers selected (intervention group) on the food guide published by the Ministry of Health "Dez passos para uma alimentação saudável: guia alimentar para crianças menores de dois anos"13. The training was provided through sessions of verbal communication between the health care team and the lead researcher of the present study, which last one hour each. In addition, the following support material was also provided to the professionals: technical pocket guide, colorful brochures to be distributed to all mothers receiving prenatal or infant care, two printed copies of the food guide, an instructional video about the food guide, and two posters that were hung in the waiting room or in the pediatric office.

The activities and services in the HCC with the control group were not changed during the study. The services were provided without the use of educational materials and without any kind of intervention or influence of the researchers.

The recruitment process took place between April and December 2008. The data 
collection team visited the HCC to identify all women in the last trimester of pregnancy enrolled in prenatal care in those centers. After signing the informed consent form, the participants answered a structured questionnaire with demographic questions (age, education, household income, marital status, occupation, parity, tabagism), and questions about the estimated date of delivery, address, and contact phone number. Their weight was measured using a digital balance Techline ${ }^{\circledR}$ (São Paulo, São Paulo, Brazil) with 100 gram precision.

Following this stage, home visits were made within six months after delivery. Data on birth and infant feeding practice in the first six months of life were collected, including the infant age when water, tea, other liquids, other types of milk or infant formula, and solid foods were introduced and the initiation and duration (in months) of exclusive breastfeeding. Maternal height was measured using a portable stadiometer (Seca ${ }^{\circledR}$, Hamburg, Germany) with 0.1 $\mathrm{cm}$ precision.

Throughout the study, the data collection team was composed of previously trained nutritionists and undergraduate nutrition students distributed according to the city region. Data were always collected by at least two team members.

Positive human immunodeficiency virus pregnant women were excluded from the study because breastfeeding is contraindicated in this situation. Women whose child was born with congenital anomalies were not included in the statistical analysis because these conditions can affect the practice of breast feeding.

Maternal nutritional status was determined using the Body Mass Index (BMI) according to gestational age, as recommended by the Ministry of Health ${ }^{14}$. Gestational age recorded in the Maternity Record Card was confirmed, which was determined based on the Last Menstrual Period (LMP) and by ultrasound. The nutritional status determined in the third trimester of pregnancy was considered in the analysis since breast feeding initiates right after this stage. Maternal nutritional status was evaluated as a dichotomous variable (normal weight, overweight) in the statistical analyses. Therefore, for comparison purposes, women that were considered as overweight or obese during pregnancy were classified in the "overweight women" group.

For the analysis of the factors associated with early discontinuation of breast feeding, the prevalence of EBF from birth to four months ( $<4$ months) of age was used. The outcome EBF $<4$ months was defined as a the situation in which the infant receives only breast milk directly from the breasts or via pumping and bottles, or breast milk from other sources, (from another woman's expressed breast milk), without the addition of any other liquid or solids except for drops or vitamin syrup, oral rehydration salts, mineral supplements, or medicine ${ }^{15}$. Exclusive breastfeeding was considered as a dichotomous variable; all women who exclusively breastfed for four months or more were classified as 'yes' and those who discontinued exclusive breastfeeding before 4 months of age and those who did not breastfeed were classified as 'no'.

Other potentially confounding factors evaluated were: random allocation of groups in the baseline study (control; intervention), maternal level of education ( $<8$ years, $\geq 8$ years of schooling), maternal age ( $<20$ years, $\geq 20$ years), household monthly income ( $\leq 3$ times the minimum wage; $>3$ times the minimum wage, considering the minimum wage value of $R \$ 415,00$ in 2008), parity (multiparity; primiparity), smoking (yes, no), infant birth weight (<2.500 grams; $\geq 2.500$ grams) and gestational age ( $<37$ weeks; $\geq 37$ weeks).

Collected data were double entered into the Statistical Package for Social Sciences (SPSS Inc., Chicago, United States of America) version 11.0. Data were validated using the Epi Info version 6.4 (Centers for Disease Control and Prevention, Atlanta, United States of America). Statistical analyses were carried out using the SPSS software version 19.0. 
Categorical variables were described by the absolute (n) and relative (\%) frequencies. The Chi-square test for linear trend was used to compare proportions. Since EBF can be influenced by multiple factors, the effect of exposure (maternal over weight) on the outcome (EBF <4 months) was assessed using Poisson regression with robust error variance, with adjustment for possible confounding variables. Wald's test of heterogeneity was used to evaluate the statistical significance of each variable in the model. The association between the independent variables and the outcome was estimated using the relative risk and its respective 95\% Confidence Intervals $(95 \% \mathrm{Cl})$. The $5 \%$ chance of rejecting the null hypothesis was accepted $(p<0.05)$.

The present study was approved by the Research Ethics Committee of the Universidade Federal de Ciências da Saúde of Porto Alegre, Resolution n 545/07, and all participants signed the Informed Consent Form.

\section{RES U L T S}

There were 736 eligible pregnant women, among which, 715 (97.1\%) agreed to participate in the study and were interviewed in the last trimester of pregnancy, constituting the baseline study. Six months after delivery, 633 mother-infant dyads continued to be monitored. The reasons for the dropouts during the follow-up period were: refusal to participate in the study $(n=29)$, change of address ( $n=11)$, death of mother and/or child or maternal mental illness or intellectual disability $(n=8)$, not found $(n=34)$, and infant with congenital disease $(n=14)$. Data collection was planned to take place six months after birth, but for logistical reasons during the follow-up period, it was extended to nine months. However, 85.6\% (530) of the mother-infant dyads were visited at home at six months postpartum.

The assessment of the nutritional status in the third trimester of pregnancy revealed that $51.0 \%$ of all pregnant women were overweight. The median duration of exclusive breastfeeding was 2.0 months. The prevalence of EBF in the first sixth months of life according to the maternal nutritional status are shown in Table 1. The prevalence of EBF in the first six months of life did not differ significantly between the eutrophic, overweight, and obese women in the third trimester of pregnancy.

Table 2 shows the effect of maternal overweight on the early discontinuation of EBF. After adjustment for possible confounding factors, there was no effect of excessive maternal overweight weight on the early discontinuation of EBF. Women who reported being smokers in the third trimester of pregnancy were 1.23 $(95 \% \mathrm{Cl}=1.13-1.35)$ times more likely to discontinue EBF than those who did not smoke. Primiparous women with less than eight years of education had slightly higher risk (1.09, $95 \% \mathrm{Cl}=1.00-1.20$ and $1.09,95 \% \mathrm{Cl}=1.00-1.21$, respectively) of discontinuing EBF than women in the other categories.

Table 1. Prevalence of exclusive breastfeeding according to maternal nutritional status among low socioeconomic women in Porto Alegre (RS), Brazil 2008-2009.

\begin{tabular}{|c|c|c|c|c|c|c|c|c|c|c|c|c|}
\hline \multirow{3}{*}{$\begin{array}{l}\text { Maternal nutritional } \\
\text { status }\end{array}$} & \multicolumn{12}{|c|}{ Exclusive breastfeeding (months) } \\
\hline & \multicolumn{2}{|c|}{$0|-| 1$} & \multicolumn{2}{|c|}{$1-12$} & \multicolumn{2}{|c|}{$2-13$} & \multicolumn{2}{|c|}{$3-14$} & \multicolumn{2}{|c|}{$4-15$} & \multicolumn{2}{|c|}{$5-16$} \\
\hline & $\mathrm{n}$ & $\%$ & $\mathrm{n}$ & $\%$ & $\mathrm{n}$ & $\%$ & $\mathrm{n}$ & $\%$ & $\mathrm{n}$ & $\%$ & $\mathrm{n}$ & $\%$ \\
\hline Eutrophic $(n=261)$ & 167 & 64.0 & 136 & 52.1 & 93 & 35.6 & 57 & 21.8 & 20 & 7.7 & 8 & 3.1 \\
\hline Overweight ( $n=147)$ & 104 & 70.7 & 92 & 62.6 & 66 & 44.9 & 41 & 27.9 & 16 & 10.9 & 5 & 3.4 \\
\hline Obese $(n=125)$ & 84 & 67.2 & 74 & 59.2 & 51 & 40.8 & 32 & 25.6 & 15 & 12.0 & 4 & 3.2 \\
\hline$p^{*}$ & \multicolumn{2}{|c|}{0.392} & \multicolumn{2}{|c|}{0.105} & \multicolumn{2}{|c|}{0.206} & \multicolumn{2}{|c|}{0.310} & \multicolumn{2}{|c|}{0.146} & \multicolumn{2}{|c|}{0.918} \\
\hline
\end{tabular}

Note: ${ }^{*}$ Chi-square test for linear trend. 
Table 2. Poisson regression model for the effect of excessive maternal weight on the early discontinuation of Exclusive Breastfeeding (EBF <4 months) among low socioeconomic status women ( $n=619)$ in Porto Alegre (RS), Brazil, 2008-2009.

\begin{tabular}{|c|c|c|c|c|c|c|c|}
\hline \multirow{2}{*}{ Variables } & \multirow[b]{2}{*}{ Total } & \multicolumn{2}{|c|}{ EBF $<4$ months } & \multicolumn{2}{|c|}{ Crude $^{a}$} & \multicolumn{2}{|c|}{ Adjusted $^{\mathbf{b}}$} \\
\hline & & $n$ & $\%$ & RR & $95 \% \mathrm{Cl}$ & $R R$ & $95 \% \mathrm{Cl}$ \\
\hline \multicolumn{8}{|l|}{ Group $^{\dagger}$} \\
\hline Control & 301 & 239 & 79.4 & 1.09 & $1.00 ; 1.19$ & 1.06 & $0.96 ; 1.16$ \\
\hline Intervention & 318 & 231 & 72.6 & 1 & & 1 & \\
\hline \multicolumn{8}{|l|}{ Education level (years) } \\
\hline$<8$ year & 192 & 159 & 82.8 & 1.13 & $1.04 ; 1.24$ & 1.09 & $1.00 ; 1.21$ \\
\hline$\geq 8$ years & 427 & 311 & 72.8 & 1 & - & 1 & \\
\hline \multicolumn{8}{|l|}{ Monthly household income ${ }^{\dagger}$} \\
\hline$\leq 3$ times the minimum wage & 424 & 331 & 78.1 & 1.09 & $0.98 ; 1.20$ & 1.04 & $0.93 ; 1.16$ \\
\hline$>3$ times the minimum wage & 177 & 127 & 71.8 & 1 & - & 1 & \\
\hline \multicolumn{8}{|l|}{ Age } \\
\hline$<20$ years & 131 & 104 & 79.4 & 1.06 & $0.96 ; 1.17$ & & \\
\hline$\leq 20$ years & 488 & 366 & 75.0 & 1 & - & - & - \\
\hline \multicolumn{8}{|l|}{ Parity } \\
\hline Primiparous & 275 & 217 & 78.9 & 1.07 & $0.98 ; 1.17$ & 1.09 & $1.00 ; 1.20$ \\
\hline Multiparous & 344 & 253 & 73.5 & 1 & - & 1 & \\
\hline \multicolumn{8}{|l|}{ Tabagism* } \\
\hline Yes & 119 & 108 & 90.8 & 1.25 & $1.15 ; 1.35$ & 1.23 & $1.13 ; 1.35$ \\
\hline No & 500 & 362 & 72.4 & 1 & - & 1 & \\
\hline \multicolumn{8}{|l|}{ Infant birth weight ${ }^{\dagger}$} \\
\hline$<2500 \mathrm{~g}$ & 39 & 30 & 76.9 & 1.01 & $0.85 ; 1.21$ & - & - \\
\hline$\geq 2500 \mathrm{~g}$ & 572 & 433 & 75.7 & 1 & - & & \\
\hline \multicolumn{8}{|l|}{ Gestational age $^{\dagger}$} \\
\hline$<37$ weeks & 39 & 29 & 74.4 & 1.00 & $0.81 ; 1.19$ & - & - \\
\hline$\geq 37$ weeks & 522 & 392 & 75.1 & 1 & - & & \\
\hline \multicolumn{8}{|l|}{ Maternal nutritional status $^{\dagger}$} \\
\hline Overweight & 272 & 199 & 73.2 & 0.93 & $0.85 ; 1.03$ & 0.95 & $0.86 ; 1.04$ \\
\hline Eutrophic & 261 & 204 & 78.2 & 1 & - & 1 & \\
\hline
\end{tabular}

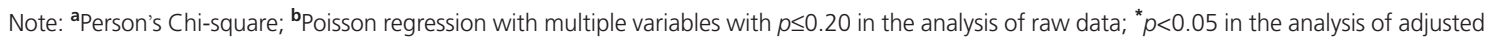
data; ${ }^{\dagger}$ Data not shown (ignored or not-obtained).

RR: Relative Risk; C195\%: 95\% Confidence Interval.

\section{I SCUSSION}

This study evaluated the effect of maternal overweight on the practice of exclusive breastfeeding among low socioeconomic status women. After risk-adjusted analysis, it was found that being overweight during pregnancy was not associated with the risk of early cessation of EBF. However, women who reported being smokers in the third trimester of pregnancy had a higher risk of discontinuing EBF than women who did not smoke.

Studies have shown the effect of maternal overweight (pre-pregnancy or weight gained during pregnancy) on the initiation and duration of breastfeeding, even when adjusted for potential confounders ${ }^{4,5,11}$. Evidence also indicates the doseresponse effect of obesity on the practice of breastfeeding, i.e., women with great degree of obesity $\left(\mathrm{BMI} \geq 35 \mathrm{~kg} / \mathrm{m}^{2}\right)$ have higher risk of stopping lactation compared to those with normal weight, overweight, and obesity class I (BMI 18.5 to $\left.34.9 \mathrm{~kg} / \mathrm{m}^{2}\right)^{5,15,16}$. However, this effect was identified only in relation to pre-pregnancy nutritional status ${ }^{5,15}$. In the present study, there was no difference in the prevalence of EBF among women who were obese prior to pregnancy and those who did not have this condition (data not 
shown). Cohort studies carried out in Greece and Denmark ${ }^{5,17}$ did not find effect of maternal overweight on breast feeding either, confirming the results obtained in the present study. These findings may be related to the differences in the designs used in the studies, breast feeding classification, maternal nutritional status, and the confounders used in data analysis ${ }^{4,17}$. Although evidence related to the effect of excessive maternal weight on breast feeding is contradictory, the risks of this condition to women's health still prevail even after delivery. It is estimated that over $70 \%$ of women retain some of the weight gained during pregnancy up to one year after giving birth $^{18}$.

We found that women who smoke had a higher risk of early cessation of EBF than those who did not smoke. The negative effect of smoking on the practice of breast feeding is wellknown and has been reported in other studies ${ }^{19,20}$. It is suggested that physiological aspects related to the consumption of nicotine affects the production of breast milk by reducing the levels of the hormone prolactin in the body, both during pregnancy and in the postpartum period ${ }^{21}$. The effect of nicotine on breast milk production may explain the fact that women who smoke during pregnancy have shorter duration of breast feeding, both exclusive and total breast feeding 20 . Moreover, it is possible that the same emotional factors that lead to smoking can negatively interfere with women's motivation to breast feed $^{22}$.

In Brazil, the Ministry of Health recommends the use of cognitive-behavioral approach to promote smoking cessation among pregnant women and the use of drugs in extreme cases $^{23}$. According to a consensus proposed by authorities of the United States and Great Britain, there is a need for an integrated approach to investigate smoking among pregnant women to offer all necessary cessation support to smokers and monitor them throughout the process ${ }^{24}$. Accordingly, intervention strategies may be effective in reducing smoking rates in this population and, consequently, in reducing risks to the newborn ${ }^{25}$.

Although primiparous women with less than eight years of education showed borderline values of risk in the risk-adjusted analysis, the association between these factors and the practice of breast feeding has been consistently reported in the scientific literature ${ }^{26-30}$. The greater vulnerability of women of lower education levels may indicate their restricted access of this population to activities promoting the practice of exclusive breastfeeding, such as easier access to information about the benefits of EBF in the first six months after birth ${ }^{27}$ and about the nutritional quality of breast milk and its importance for the healthy development of a child ${ }^{30}$. Among primiparous women, the lack of previous breast feeding experience has been associated with the early introduction of other types of milk or infant formula, whereas multiparous women have greater chance of maintaining an EBF because it is believed they have previous experience, which would facilitate adherence to this practice ${ }^{29}$.

It is worth highlighting that the extrapolation of the results obtained in the present study to other population groups of different socioeconomic status is limited since it involved low-income women only. However, the greater biological and social vulnerability of this population than that of people with better socioeconomic status indicates the need to closer monitoring and need for more studies like the present study to identify risk factors in order to facilitate the development of effective intervention strategies for promoting health, especially for the poorest population groups. Although the World Health Organization recommends EBF up to the sixth month of age ${ }^{1}$, the cut-off point to categorize prevalence of EBF was established as up to four months ( $<4$ months) due to the low prevalence of EBF up to the sixth month of life.

\section{CONCLUSION}

Based on the results obtained, excessive maternal weight was not associated with early 
discontinuation of EBF. However, it was found that smoking mothers are at increased risk of discontinuing this practice. Therefore, health care professionals should recognize the practice of smoking among pregnant women as a risk factor for early discontinuation of breast feeding. Furthermore, we highlight the importance of adequate prenatal care to promote smoking cessation during pregnancy and in the postpartum period because of the harmful effects of this habit on maternal and infant health. Although the impact of being overweight on breast feeding was not identified, excessive weight is a well-known risk factor for several diseases and should always be monitored in women both during pregnancy and in the postpartum period to contribute to the prevention of other negative effects on maternal and infant health.

\section{CONTRIBUTORS}

C DALLAZEN made a substantial contribution to data analysis and manuscript writing. MR VITOLO made a substantial contribution to the conception and design of this study, data interpretation and critical revision of the final version.

\section{REFERE N CES}

1. World Health Organization. Global strategy for infant and young child feeding. Geneva: WHO; 2003.

2. Venâncio SI, Saldiva SRDM, Monteiro CA. Tendência secular da amamentação no Brasil. Rev Saúde Pública. 2013;47(6):1205-8. https://doi.org/10.15 90/ S0034-8910.2013047004676

3. Brasil. Ministério da Saúde. Pesquisa nacional de demografia e saúde. Brasília: Ministério da Saúde; 2009.

4. Li R, Jewell S, Grummer-Strawn L. Maternal obesity and breast-feeding practices. Am J Clin Nutr. 2003;77(4):931-6.

5. Baker JL, Michaelsen KF, Sørensen TI, Rasmussen $\mathrm{KM}$. High prepregnant body mass index is associated with early termination of full and any breastfeeding in Danish women. Am J Clin Nutr. 2007;86(2):404-11.
6. Rasmussen KM, Kjolhede CL. Prepregnant overweight and obesity diminish the prolactin response to suckling in the first week postpartum. Pediatrics. 2004;113(5):e465-71. https://doi.org/ 10.1542/peds.113.5.e465

7. Jevitt C, Hernandez I, Groër M. Lactation complicated by overweight and obesity: Supporting the mother and newborn. J Midwifery Wom Heal. 2007;52(6):606-13. https://doi.org/10.1016/ j.jmwh.2007.04.006

8. Hilson JA, Rasmussen KM, Kjolhede CL. High prepregnant body mass index is associated with poor lactation outcomes among white, rural women independent of psychosocial and demographic correlates. J Hum Lact. 2004;20(1):18-29. https://doi.org/10.1177/0890 334403261345

9. Lacoursiere DY, Baksh L, Bloebaum L, Varner MW. Maternal body mass index and self-reported postpartum depressive symptoms. Matern Child Health J. 2006;10(4):385-90. https://doi.org/ 10.1007/s10995-006-0075-1

10. Turcksin R, Bel S, Galjaard S, Devlieger R. Maternal obesity and breastfeeding intention, initiation, intensity and duration: A systematic review. Matern Child Nutr. 2014;10(2):166-83. https://doi.org/ 10.1111/j.1740-8709.2012.00439

11. Fernandes TA, Werneck GL, Hasselmann MH. Prepregnancy weight, weight gain during pregnancy, and exclusive breastfeeding in the first month of Life in Rio de Janeiro, Brazil. J Hum Lact. 2012;28(1):55-61. https://doi.org/10.1177/0890 334411429113

12. Instituto Brasileiro de Geografia e Estatística. Orçamento e gestão pesquisa de orçamentos familiares 2008-2009: antropometria e estado nutricional de crianças, adolescentes e adultos no Brasil. Rio de Janeiro: IBGE; 2010.

13. Brasil. Ministério da Saúde. Dez passos para uma alimentação saudável: guia alimentar para crianças menores de dois anos. Brasília: Ministério da Saúde; 2002.

14. Brasil. Ministério da Saúde. Secretaria de Atenção à Saúde. Obesidade. Brasília: Ministério da Saúde; 2006. Cadernos de Atenção Básica, nº 12.

15. Liu J, Smith MG, Dobre MA, Ferguson JE. Maternal obesity and breast-feeding practices among white and black women. Obesity. 2010;18(1):175-82.

16. Garcia AH, Voortman T, Baena CP, Chowdhurry R, Muka T, Jaspers L, et al. Maternal weight status, diet, and supplement use as determinants of breastfeeding and complementary feeding: A systematic review and meta-analysis. Nutr Rev. 2016;74(8):490-516. https://doi.org/10.1093/ nutrit/nuw016 
17. Manios Y, Grammatikaki E, Kondaki K, loannou E, Anastasiadou A, Birbilis M. The effect of maternal obesity on initiation and duration of breast-feeding in Greece: The Genesis study. Public Health Nutr. 2009;12(4):517-24. https://doi.org/10.1017/S13 68980008002838

18. Nast M, Oliveira A, Rauber F, Vitolo MR. Ganho de peso excessivo na gestação é fator de risco para o excesso de peso em mulheres. Rev Bras Ginecol Obstet. 2013;35(12):536-40. https://doi.org/10. 1590/S0100-72032013001200002

19. Weiser TM, Lin M, Garikapaty V, Feyerharm RW, Bensyl DM, Zhu BP. Association of maternal smoking status with breastfeeding practices: Missouri, 2005. Pediatrics. 2009;124(6):1603-10. https://doi.org/10.1542/peds.2008-2711

20. Bahadori B, Riediger ND, Farrell SM, Uitz E, Moghadasian MF. Hypothesis: Smoking decreases breast feeding duration by suppressing prolactin secretion. Med Hypotheses. 2013;81(4):582-6. https://doi.org/10.1016/j.mehy.2013.07.007

21. Glintborg D, Mumm H, Hougaard DM, Ravn P, Andersen M. Smoking is associated with increased adrenal responsiveness, decreased prolactin levels and a more adverse lipid profile in 650 white patients with polycystic ovary syndrome. Gynecol Endocrinol. 2012;28(3):170-4. https://doi.org/ 10.3109/09513590.2011.589926

22. Silveira FJ, Lamounier JA. Factors associated with breastfeeding duration in three cities in the region of Alto Jequitinhonha, Minas Gerais, Brazil. Cad Saúde Pública. 2006;22(1):69-77. https://doi.org/ 10.1590/S0102-311X2006000100008

23. Instituto Nacional do Câncer. Abordagem e tratamento do fumante: consenso 2001. Rio de Janeiro: Inca; 2001.
24. Aveyard P, West R. Managing smoking cessation. BMJ. 2007;335(7609):37-41. https://doi.org/10. 1136/bmj.39252.591806.47

25. Lumley J, Chamberlain C, Dowswell T, Oliver S, Oakley L, Watson L. Interventions for promoting smoking cessation during pregnancy. Cochrane Database Syst Rev. 2009(3):CD001055. https:// doi. org/10.1002/14651858.CD001055.pub3

26. Nascimento MB, Reis MA, Franco SC, Issler $H$, Ferraro AA, Grisi SJ. Exclusive breastfeeding in southern Brazil: Prevalence and associated factors. Breastfeed Med. 2010;5(2):79-85. https://doi.org/ 10.1089/bfm.2009.0008

27. Alves AL, Oliveira MI, Moraes JR. BreastfeedingFriendly Primary Care Unit Initiative and the relationship with exclusive breastfeeding. Rev Saúde Pública. 2013;47(6):1130-40. https://doi.org/10. 1590/S0034-8910.2013047004841

28. Venancio SI, Saldiva SR, Mondini L, Levy RB, Escuder MM. Early interruption of exclusive breastfeeding and associated factors, state of São Paulo, Brazil. J Hum Lact. 2008;24(2):168-74. https://doi.org/ 10.1177/0890334408316073

29. Salustiano LP, Diniz AL, Abdallah VO, Pinto ReM. Fatores associados à duração do aleitamento materno em crianças menores de seis meses. Rev Bras Ginecol Obstet. 2012;34(1):28-33. https://doi. org/10.1590/S0100-72032012000100006

30. Azevedo DS, Reis ACS, Freitas LV, Costa PB, Pinheiro PNC, Damasceno AKC. Conhecimento de primíparas sobre os benefícios do aleitamento materno. Rev Rene. 2010;11(2):53-62. https://doi.org/10.15 90/S1415-52732002000100004

Received: February 23, 2016 Final version: July 20, 2016 Approved: September 29, 2016 
